Andreane FILAPPI ${ }^{1}$

Danívia PRESTES ${ }^{1}$

Bruna GARMATZ

Sônia dos Anjos LOPES ${ }^{1}$

Marcelo CECIM

Correspondência para:

Marcelo Cecim, Departamento

de Clínica de Grandes Animais, Hospital Veterinário,UFSM, Campus, 97105-900, Santa Maria - RS, Brasil.

E-mail:mcecim@smail.ufsm.br

Recebido para publicação: 23/03/2007 Aprovado para publicação: 31/01/2008

\title{
Influência da administração crônica de fluoreto de sódio na função e histologia hepática de ovinos
}

\author{
1 - Universidade Federal de Santa Maria, Santa Maria - RS
}

\section{Resumo}

O objetivo do presente estudo foi o de investigar o efeito da ingestão acumulativa de fluoreto de sódio sobre o metabolismo hepático de ovinos. O experimento foi conduzido com 12 animais da raça Texel $\mathrm{x}$ Ile de France, os quais foram divididos em dois grupos iguais. $\mathrm{O}$ grupo controle recebeu sal iodado $(5 \mathrm{~g} \mathrm{de} \mathrm{NaCl} /$ animal $+0,2 \mathrm{ppm} \mathrm{I}$ / $\mathrm{kg}$ matéria seca) e o grupo tratado, o mesmo sal iodado adicionado de fluoreto de sódio (4,7 $\mathrm{mg} \mathrm{F} / \mathrm{kg}$ de peso corporal), diariamente, por um período de 150 dias. Amostras de sangue foram coletadas aos 60 , 90, 120 e 150 dias de tratamento. Ainda, nesses mesmos momentos, com uma coleta também no tempo zero, os animais foram alojados em gaiolas metabólicas para obtenção de urina produzida em 24 horas. Após o sacrifício dos animais, uma amostra de fígado foi removida para avaliação histológica. Verificou-se elevação nas concentrações séricas e urinárias de F no grupo tratado. Quanto às concentrações séricas de proteína total, albumina e colesterol total, não houve diferença significativa entre os grupos, assim como não houve na atividade das enzimas gama glutamiltransferase e aspartato aminotransferase. No exame histológico do fígado, não foram observadas alterações. A administração de fluoreto de sódio na dose e duração deste estudo não induz a hepatotoxicidade.

\section{Introdução}

O flúor (F) é um elemento traço essencial para o organismo. No entanto, a exposição ao F por um período prolongado pode ser nociva à saúde de animais de produção, resultando em perdas econômicas. ${ }^{1}$ A essencialidade do F em seres humanos está relacionada, em pequenas quantidades, à saúde dentária. ${ }^{2}$ No entanto, para ruminantes, o interesse biológico deste elemento está confinado aos seus efeitos tóxicos. Bovinos e ovinos são especialmente sensíveis. Para esses animais, no Brasil, a fonte de F mais freqüente provém do suplemento mineral e, mais especificamente, da fonte de fósforo (P). Como o P e F participam da mesma molécula de apatita, as disponibilidades biológicas de ambos estão interligadas. ${ }^{1}$

A maior parte do F ingerido é incorporada aos tecidos calcificados, mas pequenas quantidades podem alterar algumas atividades enzimáticas e metabólicas nos tecidos moles. ${ }^{3}$ A fluorose pode causar danos em muitos tecidos ${ }^{4}$, dentre os quais se destacam o ósseo, dentário, nervoso, renal e hepático ${ }^{5}$. Por ser o fígado um sítio ativo do metabolismo corporal, está especialmente susceptível a intoxicação pelo $\mathrm{F}^{6}$ Investigações epidemiológicas indicam que anormalidades metabólico-funcionais e mudanças histopatológicas ocorrem em diferentes espécies como ovinos, bovinos e ratos ${ }^{7,8,9}$, contudo o mecanismo dessas alterações não está bem esclarecido. Estudos prévios demonstram que esse elemento, no fígado, pode produzir alterações inflamatórias e degenerativas ${ }^{6}$, dilatação de sinusóides e hiperplasia celular ${ }^{10}$.

$\mathrm{O}$ objetivo do presente estudo foi investigar o efeito da ingestão acumulativa de fluoreto de sódio sobre o metabolismo hepático por meio da determinação dos teores séricos de proteína total (PT), 
albumina e colesterol total (CT), assim como da atividade das enzimas gama glutamiltransferase (GGT) e aspartato aminotransferase (AST) e exame histológico do tecido hepático.

\section{Material e Método}

Foram utilizados 12 ovinos, machos, inteiros, mestiços das raças Texel x Ile de France, com idade aproximada de 10 meses, pesando entre 33 e $40 \mathrm{~kg}$. Durante o período experimental, os animais foram mantidos em baias e receberam como dieta diária o equivalente a $3 \%$ do peso vivo de feno de alfafa e água ad libitum. Após um período de adaptação de 15 dias, os animais foram divididos em dois grupos de seis ovinos cada. O grupo controle recebeu sal iodado $(5 \mathrm{~g}$ de $\mathrm{NaCl} /$ animal $+0,2 \mathrm{ppm} \mathrm{I} / \mathrm{kg} \mathrm{MS})$ e o grupo tratado, o mesmo sal iodado adicionado de fluoreto de sódio $(4,7 \mathrm{mg} \mathrm{F}$ / $\mathrm{kg}$ de peso corporal), sendo diluído os sais em água destilada, administrado via sonda oro-esofágica, diariamente, por um período de 150 dias.

Amostras de sangue da veia jugular foram coletadas aos 60, 90, 120 e 150 dias de tratamento. Ainda, nesses mesmos momentos, com uma coleta também no tempo zero, os animais foram alojados em gaiolas metabólicas para obtenção de urina produzida em 24 horas. Para avaliação da função hepática, determinaram-se as concentrações séricas de PT, albumina e CT e a atividade das enzimas GGT e AST. Os teores de PT e albumina foram mensurados por determinação colorimétrica por meio de Kit comercial (Proteínas Totais Labtest ${ }^{\circledR}$; Albumina Labtest $\left.{ }^{\circledR}\right)$. Para determinação das PT foi utilizado o método do Bioreto, de acordo com técnica descrita por Gornall, Bardawill e David ${ }^{11}$, modificado por Strufaldi ${ }^{12}$. A taxa de albumina plasmática foi determinada utilizando o método do verde de bromocresol. O colesterol total plasmático foi determinado através de método enzimático colorimétrico utilizando kit comercial (Colesterol liquiform Labtest $\left.{ }^{\circledR}\right)$, de acordo com metodologia de
Schimid e von Forstner ${ }^{13}$. A atividade enzimática da GGT foi determinada por método modificado por Szasz ${ }^{14}$ utilizandose kit enzimático comercial (Gama GT liquiform Labtest $\left.{ }^{\circledR}\right)$. A atividade da AST foi determinada de acordo com a metodologia descrita por Bergmeyer ${ }^{15}$ através de Kit comercial (AST/GOT liquiform Labtest $\left.{ }^{\circledR}\right)$. As concentrações de $F$ nas amostras séricas e urinárias foram detectadas potenciometricamente por meio de eletrodo íon seletivo de acordo com técnica recomendada por Eaton, Clesceri e Greenberg ${ }^{16}$. A temperatura que o método foi desenvolvido foi de $25^{\circ} \mathrm{C}$.

Após o sacrifício dos animais, uma amostra de fígado foi removida e fixada em formol a $10 \%$. Como coloração utilizou-se hematoxilina-eosina para posterior exame histopatológico.

Os resultados foram expressos em média \pm desvio padrão. As médias nos diferentes tempos e entre grupos foram estudadas por análise de variância (ANOVA), e a seguir submetidos ao teste "post-hoc" de Tukey. A eliminação de F na urina em decorrência do tempo de exposição nos animais tratados foi analisado pelo coeficiente de correlação de Pearson.

\section{Resultados}

Em relação à concentração sérica $\mathrm{e}$ urinária de $\mathrm{F}$, houve diferença significativa $(\mathrm{P}<0,001)$ entre os grupos controle e tratado nos diferentes momentos estudados. Em cada grupo, não foi observada diferença significativa, entre momentos, no que se refere à concentração sérica de $\mathrm{F}(\mathrm{P}>0,05)$. Quanto à concentração urinária de F, no grupo tratado, houve diferença significativa $(\mathrm{P}<0,01)$ entre os momentos zero, 60, $120 \mathrm{e}$ 150 dias (Tabela 1 ).

$\mathrm{Na}$ análise do perfil protéico sérico, não foram observadas diferenças $(\mathrm{P}>0,05)$ nas concentrações de PT e albumina na comparação entre os grupos controle e tratado, assim como entre momentos no mesmo grupo. Similarmente, não foram observadas diferenças na atividade das 
enzimas GGT e AST, e na concentração sérica de colesterol total (Tabela 2).

No exame histológico do fígado, o padrão lobular foi similar nos grupos tratado e controle. Em ambos os grupos, não foi observada degeneração hialina ou evidência de proliferação e/ou pigmentação anormal das células de Kupffer's, alterações observadas quando da intoxicação por F. Também não foram constatadas necrose do tipo focal nas células hepáticas, infiltração na região periportal e dilatação dos sinusóides hepáticos.

\section{Discussão}

A dose de $F$ utilizada neste experimento $(4,7 \mathrm{mg} \mathrm{F} / \mathrm{kg}$ de peso corporal) foi baseada em estudo prévio realizado por Kessabi, Hamliri e Braun ${ }^{7}$ em ovinos, no qual foi capaz de produzir um quadro de fluorose (dental e esquelética) e, alterações em órgãos como fígado e rins.

Uma vez que a urina é a principal via de excreção do F, o incremento do F urinário é usado para o diagnóstico específico e confiável de fluorose ${ }^{17}$. Neste estudo, a

Tabela 1 - Médias \pm desvios padrão de teores de flúor no soro e urina de ovinos tratados ou não com fluoreto de sódio (4,7 mg F/kg de peso corporal) em diferentes momentos, Santa Maria - RS, novembro de 2005 a abril de 2006

\begin{tabular}{|c|c|c|c|c|}
\hline \multirow[b]{2}{*}{ Grupo } & \multirow[b]{2}{*}{ Momentos (dias) } & \multirow[b]{2}{*}{ Soro $(\mathrm{mg} / \mathbf{L})$} & \multicolumn{2}{|c|}{ Urina } \\
\hline & & & $\mathrm{mg} / \mathrm{L}(24 \mathrm{~h})$ & Total (mg 24 h) \\
\hline \multirow{5}{*}{ Controle $(n=6)$} & 0 & $\cdots$ & $0,60 \pm 0,23 a$ & $0,41 \pm 0,38 a$ \\
\hline & 60 & $0,16 \pm 0,03 a$ & $0,44 \pm 0,10 \mathrm{a}$ & $0,64 \pm 0,09 a$ \\
\hline & 90 & $0,10 \pm 0,01 a$ & $0,80 \pm 0,43 a$ & $0,46 \pm 0,19 a$ \\
\hline & 120 & $0,15 \pm 0,02 \mathrm{a}$ & $0,90 \pm 0,23 a$ & $0,53 \pm 0,18 a$ \\
\hline & 150 & $0,12 \pm 0,02 \mathrm{a}$ & $0,68 \pm 0,17 a$ & $0,46 \pm 0,08 \mathrm{a}$ \\
\hline \multirow{5}{*}{ Tratado $(n=6)$} & 0 & $\cdots$ & $0,45 \pm 0,07 a$ & $0,34 \pm 0,13 a$ \\
\hline & 60 & $0,41 \pm 0,10 \mathrm{~b}$ & $18,04 \pm 3,58 b$ & $30,59 \pm 10,12 b$ \\
\hline & 90 & $0,38 \pm 0,05 b$ & $22,30 \pm 4,75 b c$ & $31,95 \pm 8,52 \mathrm{bc}$ \\
\hline & 120 & $0,38 \pm 0,08 b$ & $27,79 \pm 6,79 \mathrm{c}$ & $38,87 \pm 9,15 \mathrm{bcd}$ \\
\hline & 150 & $0,39 \pm 0,08 b$ & $29,77 \pm 8,26 \mathrm{c}$ & $52,65 \pm 9,80 \mathrm{~d}$ \\
\hline
\end{tabular}

Letras diferentes indicam diferença significativa $(\mathrm{P}<0,01)$ entre médias dentro da coluna; ... Dado não existente

Tabela 2 - Médias \pm desvios padrão de proteína total (PT), albumina, gama glutamiltransferase (GGT), aspartato aminotransferase (AST) e colesterol total (CT) no soro de ovinos tratados ou não com fluoreto de sódio (4,7 mg F/kg de peso corporal) em diferentes momentos, Santa Maria - RS, novembro de 2005 a abril de 2006

\begin{tabular}{ccccccc}
\hline & $\begin{array}{c}\text { Momentos } \\
\text { Grupo }\end{array}$ & PT & Albumina & GGT & AST & CT \\
\hline Controle & 90 & $63,30 \pm 3,30$ & $35,30 \pm 3,60$ & $89,07 \pm 2,96$ & $76,50 \pm 13,63$ & $1,09 \pm 0,13$ \\
$(\mathbf{n = 6 )}$ & 120 & $65,50 \pm 3,60$ & $\ldots$ & $80,55 \pm 6,35$ & $80,67 \pm 7,12$ & $0,91 \pm 0,11$ \\
& 150 & $62,30 \pm 3,30$ & $35,8 \pm 3,10$ & $95,73 \pm 12,16$ & $100,83 \pm 28,81$ & $1,19 \pm 0,28$ \\
\hline \multirow{2}{*}{ Tratado } & 90 & $64,50 \pm 2,20$ & $33,0 \pm 6,20$ & $88,60 \pm 9,90$ & $70,83 \pm 11,79$ & $1,06 \pm 0,06$ \\
$(=6)$ & 120 & $65,00 \pm 8,20$ & $\ldots$ & $81,63 \pm 8,41$ & $72,83 \pm 7,36$ & $0,92 \pm 0,13$ \\
& 150 & $62,80 \pm 2,70$ & $35,50 \pm 1,00$ & $96,73 \pm 9,41$ & $104,60 \pm 28,41$ & $1,12 \pm 0,12$ \\
\hline
\end{tabular}

Não existe diferença significativa $(\mathrm{P}>0,05)$ entre os diferentes grupos e momentos para todas as variáveis; ... Dado não existente. 
concentração de $\mathrm{F}$ urinário em ovinos tratados diariamente com 4,7 mg F/ $\mathrm{kg}$ de peso corporal por um período de 150 dias foi significativamente maior do que no grupo controle. A excreção de F na urina do grupo tratado ocorreu de forma crescente ao longo do período experimental $(r=0,88)$. Esse fato também foi observado por Cenesiz et al. ${ }^{18}$ ao administrar diariamente $1,8 \mathrm{mg} \mathrm{F} / \mathrm{kg}$ de peso corporal para ovinos durante 24 semanas. Esses autores observaram ao final do trabalho um incremento de $\mathrm{F}$ urinário de 0,9 ppm para 8 ppm, com manifestação clínica de fluorose. Conforme Masfield ${ }^{17}$, esse índice de excreção indica um quadro de fluorose crônica. No entanto, os ovinos tratados com $\mathrm{F}$ no presente experimento apresentaram valores de $\mathrm{F}$ urinário, em média, três vezes superiores aos observados por Cenesiz et al. ${ }^{18}$, porém sem manifestação de sintomas clínicos de fluorose. Considerando que, os animais são protegidos dos efeitos tóxicos do F por dois mecanismos fisiológicos, a excreção urinária e a deposição de $\mathrm{F}$ nos ossos ${ }^{1}$, acredita-se que esses mecanismos sejam os responsáveis pela ausência de quaisquer efeitos tóxicos com manifestações clínicas dentárias e ósseas nos animais deste experimento, muito embora, os valores séricos de $\mathrm{F}$ encontravam-se aumentados.

Estudos prévios indicam que a relação do F sérico com o grau de fluorose tem resultados variáveis. ${ }^{19,20} \mathrm{~A}$ administração de altas quantidades de $\mathrm{F}$ na dieta tende a elevar os teores de F não somente na urina, mas também no soro sangüíneo. ${ }^{21}$ Quanto à concentração de $\mathrm{F}$ sérica deste experimento, houve um incremento significativo no grupo tratado, mantendose constante durante todo o período experimental. Similarmente, estudo realizado com seres humanos revelou concentrações séricas de $\mathrm{F}$ superiores no grupo que consumiu maiores quantidades de $\mathrm{F}$ na água de beber. ${ }^{22} \mathrm{O} F$ ingerido pode ter sua absorção gastrintestinal reduzida na presença de altas concentrações de cálcio na dieta, devido à formação de complexos insolúveis com esse elemento. A análise do feno de alfafa fornecido diariamente aos animais neste estudo continha teores de cálcio de 18,9 $\mathrm{g} / \mathrm{kg}$ MS, superiores aos requerimentos diários para a espécie e categoria em questão, que é de $2,4 \mathrm{~g} / \mathrm{kg} \mathrm{MS} .{ }^{1}$ No entanto, isto não impediu a absorção, uma vez que foi constatada presença de concentrações séricas elevadas e de altos teores de excreção na urina de $\mathrm{F}$.

O fígado é um importante órgão para o metabolismo e desintoxicação. No presente trabalho foram avaliadas algumas variáveis bioquímicas do sangue indicativas da função hepática, visando verificar possíveis alterações induzidas pelo F. Não foram observadas diferenças significativas entre os grupos controle e tratado nas concentrações de PT e albumina, ambas mantendo-se no intervalo de referência para espécie. ${ }^{23}$ Todavia, investigações anteriores com diferentes espécies animais, reportam decréscimos significativos nos teores séricos destas variáveis induzidas pelo tratamento com NaF.3, ${ }^{3,24,25}$ Quanto às concentrações de GGT, AST e CT obtidas no presente estudo, também não foram observadas diferenças entre os grupos controle e tratado. Contrariamente, em estudos conduzidos com coelhos e ratos, houve decréscimo nas concentrações destes metabólitos nos grupos tratados com $\mathrm{NaF}^{2,26,27}$

Neste experimento, a ausência de mudanças no perfil sérico dos teores de PT, albumina, CT, GGT e AST foi concordante com a constatação de integridade histológica do fígado. Alguns autores citam alterações nas variáveis bioquímicas indicadoras da função hepática associados aos efeitos hepatotóxicos do $\mathrm{NaF}$, confirmadas pelas alterações da histologia do órgão. ${ }^{10,27}$ Os dados obtidos neste estudo mostram que mesmo expostos a teores tóxicos por um longo período de tempo os ovinos jovens mestiços de raças de carne em fase final de crescimento, são altamente tolerantes à ingestão de altas doses de flúor. Tal conceito já foi emitido anteriormente por McDowell ${ }^{28}$, o qual cita que esses animais podem tolerar até 2,5 vezes mais $F$ na 
dieta do que ovinos adultos de raças produtoras de lã.

\section{Conclusão}

Embora a ingestão prolongada de altas doses de flúor provoque um aumento da concentração sangüínea desse mineral, existe em concomitância uma grande excreção urinária desse elemento, não causando qualquer sinal evidente de hepatotoxicidade.

\title{
Influence of the chronic administration of sodium fluoride in ovine hepatic function and histology
}

\begin{abstract}
The objective of the present study was to investigate the effect a prolonged and high of sodium fluoride intake on liver metabolism in ovine. The trial involved 12 Texel x Ile de France animals, which were divided into two equal groups. The control group was treated daily with iodized salt $(5 \mathrm{~g} \mathrm{NaCl} /$ animal $+0.2 \mathrm{ppm} \mathrm{I} / \mathrm{kg}$ dry matter $)$ and the experimental group, with received the same iodized salt added of sodium fluoride (4.7 $\mathrm{mg} \mathrm{F} / \mathrm{kg}$ body weight) for 150 days. Blood samples were collected on days 60, 90, 120 and 150 of the treatment. Besides, on same days and with samples collected also at time zero, animals were placed in metabolic cages for a 24-h collection of urine samples. After animals were euthanized, a liver sample was collected for histological analysis. Fluoride concentrations in the serum and urine were increased in the experimental group. No statistical differences were observed in total protein, albumin and total cholesterol serum concentrations, and in the activities of the enzymes gamma glutamyl transferase and aspartate aminotransferase. No changes were observed in the histological analysis of the liver. The administration of sodium fluoride in the dose used and during the period analyzed in the present study does not lead to hepatotoxicity.
\end{abstract}

Key words:

Fluoride. Sheep.

\section{Referências}

1 UNDERWOOD, E. J.; SUTTLE, N. F. The mineral nutrition of livestock. 3. ed. London: CAB Internacional, 1999. $664 \mathrm{p}$.

$2 \mathrm{LI}, \mathrm{L}$. The biochemistry and physiology of metallic fluoride: Action, mechanism and implications. Clinical Reviews in Oral Biology \& Medicine, v. 14, n. 2, p. 100-114, 2003.

3 BOUAZIZ, $\mathrm{H}$. et al. Effects of sodium fluoride on hepatic toxicity in adult mice and their suckling pups. Pesticide Biochemistry and Physiology, v. 86, n. 3, p. 124-130, 2006.

$4 \mathrm{LI}$, J. X.; CAO, S. R. Recent studies on endemic fluorosis in China. Fluoride, v. 27, n. 3, p. 125-128, 1994.

5 WANG, A. G. et al. Antagonistic effects of selenium on oxidative stress and apoptosis induced by fluoride in human hepatocytes. Fluoride, v. 37, n. 2, p. 107116, 2004.

6 CHINOY, N. J.; SHARMA, M.; MICHAEL, M.
Beneficial effects of ascorbic acid and calcium on reversal of fluoride toxicity in male rats. Fluoride, v. 26, p. 4556, 1993.

7 KESSABI, M.; HAMLIRI, A.; BRAUN, J. P. Experimental fluorosis in sheep: alleviating effects of aluminium. Veterinary Human Toxicology, v. 28, n. 4, p. 300-304, 1986.

8 KOLODZIEJCZYK, A.; PUT, A.; GRZELA, P. Liver morphology and histochemistry in rats resulting from ingestion of sodium selenite and sodium fluoride. Fluoride, v. 33, n. 1, p. 6-16, 2000.

9 CHINOY, N. J.; MEMON, M. R. Beneficial effects of some vitamins and calcium on fluoride and aluminium toxicity on gastrocnemius muscle and liver of male mice. Fluoride, v. 34, n. 1, p. 21-33, 2001.

10 SHASHI, A.; THAPAR, S. P. Histopathology of fluoride-induced hepatotoxicity in rabbits. Fluoride, $\mathrm{v}$. 34 , n. 1, p. 34-42, 2001

11 GORNALL, A. G.; BARDAWILL, G. J.; DAVID, M. M. Determination of serica proteins by mean of biuret. Journal of Biological Chemie, v. 1, n. 117, p. 751-761, 
1949.

12 STRUFALDI, B. Prática de bioquímica clínica. São Paulo: Faculdade de Ciências Farmacêuticas da Universidade de São Paulo, 1987. 399 p.

13 SCHIMID, M.; von FORSTNER. Laboratory testing in the veterinary medicine and clinical monitoring. Mannheim: Boehringer, 1986. 253 p.

14 SZASZ, G. A kinetic photometric method for serum gamma-glutamyltranspeptidase. Clinical Chemistry, v. 15, n. 2, p. 124-135, 1969.

15 BERGMEYER, H.U. Methods of enzymatic analysis. San Diego: Academic Press, 1974. 572 p.

16 EATON, A. D.; CLESCERI, L. S.; GREENBERG, A. E. Standard methods for the examination of water and wastewater. Washington: American Public Health Association, 1995. $1018 \mathrm{p}$

17 MASFIELD, P. The distribution of urinary fluoride concentration in the UK. Fluoride, v. 32, n. 1, p. 27 32, 1999.

18 CENESIZ, S. et al. Chronic effects of fluoride in Tuj sheep on serum levels of total protein , albumin, uric acid and nitric oxide and activities of lactate dehydrogenase and leucine aminopeptidase. Fluoride, v. 38, n. 1, p. 52-56, 2005.

19 SONG, C. F.; HUANG, W. Y.; YAN, B. W. Relationship of blood chemistry and state of skeletal fluorosis inpatients induced by coal combustion pollution. Chinese Journal Endemiology, v. 14, n. 5, p. 291-293, 1995.

20 ZHOU, Z. R. et al. Discussion of effects on chemistry indexes of patients with skeletal fluorosis after improving water. Chinese Journal of Control Endemic Diseases, v. 12 , n. 1, p. 50-51, 1997.

21 SHARMA, A.; CHINOY, N. J. Role of free radicals in fluoride-induced toxicity in liver and kidney of mice and its reversal. Fluoride, v. 31, n. 3, p. S26, 1998.

$22 \mathrm{XIONG}, \mathrm{X}$. et al. Dose-effect relationship between drinking water fluoride levels and damage to liver and kidney function in children. Environmental Research, v. 103, n. 1, p. 112-116, 2007.

23 KANEKO, J. J.; HARVEY, J. W.; BRUSS, M. L. Clinical biochemistry of domestic animals. 5. ed. San Diego: Academic Press, 1997. 932 p.

24 SHASHI, A.; SINGH, J. P.; THAPAR, S. P. Protein degradation in skeletal muscle of rabbit during experimental fluorosis. Fluoride, v. 25, n. 3, p. 155158, 1992.

25 PAUL, V.; EKAMBARAM, A. R.; JAYAKUMAR, A. $R$. Effects of sodium fluoride on locomotor behaviour and a few biochemical parameters in rats. Environmental Toxicology Pharmacology, v. 6, n. 3, p. 187-191, 1998.

26 PILLAI, K. S.; MANE, U. H. Effect of airborne fluoride on some haemato-logical parameters of chick. Bulletin of Environmental Contamination and Toxicology, v. 35, n. 1, p. 510-516, 1985.

$27 \mathrm{SHASHI}$ A. In vivo studies concerning toxic effects of sodium fluoride on hepatic function in rabbits. Fluoride, v. 36, n. 1, p. 30-37, 2003.

28 McDOWELL, L. R. Minerals in animal and human nutrition. San Diego: Academic Press, 1992. 524 p. 